\title{
Body weight, height and ethnicity are the best predictors of fracture load at the tibia in UK dwelling South Asian and Caucasian postmenopausal women
}

\author{
A. L. Darling, O. A. Hakim, K. H. Hart and S. A. Lanham-New \\ Division of Nutritional Sciences, Faculty of Health and Medical Sciences, University of Surrey, Guildford, GU2 7XH, UK
}

There is a controversy as to whether ethnicity has a true influence on bone health. Indeed, some ${ }^{(1)}$, but not all ${ }^{(2)}$ studies have found that ethnicity is not a significant predictor of bone density if body size is controlled for in the analysis. In addition, there is a considerable lack of research into bone health in different ethnic groups, and the dietary, lifestyle and anthropometric predictors of bone health, especially in South Asians (SA). In summer 2010, $n=21$ postmenopausal SA women (mean age 63.3 y (3.7)) and $n=61$ postmenopausal C women (mean age 65.9y (4.7)) took part in the repeat of the D-FINES study (Vitamin D, Food Intake, Nutrition and Exposure to Sunlight in Southern England). A peripheral quantitative computed tomography (pQCT) scan (Stratec, XTC2000) was undertaken of the tibia (lower leg) and radius (forearm) to assess indices of bone strength. Also, subjects completed a 4 day diet diary (photographic estimation method) and relevant anthropometric and lifestyle information was obtained. Bone fracture load is the theoretical force (in Newtons; $\mathrm{N}$ ) required to break a bone. This is estimated using the pQCT computer software from the bone scan measurements taken. Multiple regression was run using PASW 18.0 to examine relative ability of age, ethnicity, body weight, height, protein and dietary protein, energy, calcium, vitamin D and sodium to predict bone fracture load. Dietary under-reporters (defined by those showing energy:BMR ratio of less than 1.0) were excluded from the analysis.

\begin{tabular}{|c|c|c|c|c|c|c|c|c|}
\hline \multirow[b]{2}{*}{ Variables } & \multicolumn{4}{|c|}{ Tibia X3 Fracture Load (N) } & \multicolumn{4}{|c|}{ Tibia Y3 Fracture Load (N) } \\
\hline & $\mathrm{B} \neq$ & SE & $\operatorname{Beta}^{\wedge}$ & $p$ & $\mathrm{~B} \neq$ & SE & $\operatorname{Beta}^{\wedge}$ & $\bar{p}$ \\
\hline Constant & -5961.12 & 3262.59 & - & 0.08 & -5755.22 & 2638.18 & - & 0.04 \\
\hline Ethnicity** & -1101.82 & 356.78 & -0.42 & 0.00 & -685.56 & 288.50 & -0.34 & 0.02 \\
\hline Age (years) & 13.86 & 18.82 & 0.08 & 0.47 & 12.53 & 15.22 & 0.09 & 0.42 \\
\hline Weight (Kg) & 26.52 & 9.99 & 0.30 & 0.01 & 23.51 & 8.08 & 0.35 & 0.01 \\
\hline Height (Kg) & 44.98 & 14.96 & 0.40 & 0.01 & 38.24 & 12.09 & 0.44 & 0.00 \\
\hline$*$ Protein $(\mathrm{g} / \mathrm{d})$ & -0.26 & 4.76 & -0.01 & 0.96 & 3.27 & 3.85 & 0.12 & 0.40 \\
\hline *Energy (kcal/d) & 0.00 & 0.26 & 0.00 & 1.00 & -0.03 & 0.21 & -0.02 & 0.87 \\
\hline *Vitamin D (ug/d) & 20.31 & 50.93 & 0.04 & 0.69 & 42.65 & 41.19 & 0.12 & 0.31 \\
\hline$*$ Calcium $(\mathrm{mg} / \mathrm{d})$ & 0.28 & 0.51 & 0.07 & 0.59 & 0.16 & 0.41 & 0.06 & 0.69 \\
\hline *Sodium (mg/d) & 0.13 & 0.10 & 0.14 & 0.22 & 0.06 & 0.08 & 0.09 & 0.45 \\
\hline Overall Model & \multicolumn{4}{|c|}{$\mathrm{F}=0.7 .611 p<0.001$} & \multicolumn{4}{|c|}{$\mathrm{F}=6.597 p<0.001$} \\
\hline
\end{tabular}

* Dietary intakes of nutrients; ** SA $=1, \mathrm{C}=0 ;$ coefficients- $\neq$ unstandardised; ${ }^{\wedge}$ standardized.

Models for the radius X3 $(\mathrm{F}=1.358, p=0.242)$, and $\mathrm{Y} 3(\mathrm{~F}=1.353, p=0.244)$ were not statistically significant. For the tibia, the only significant predictors of fracture load were ethnicity, and body height and weight (see table). Ethnicity was the strongest predictor of fracture load, with the negative coefficient showing that SA have a lower fracture load than the C women. This suggests that lifestyle, body composition and genetic differences relevant to ethnicity may be of importance here. The importance of increased body weight and height is likely due to the beneficial effect of a higher weight bearing load on bone strength, as well as possibly hormonal factors such as a higher fat mass correlating with an increased oestrogen supply, which is beneficial for bone health. Age was not a significant predictor of fracture load. This is likely due to the low variability in age of the participants in the study. Further work is underway to examine the influence of key dietary factors as significant predictors of bone fracture load.

The repeat D-FINES study was funded by a University of Surrey PhD studentship for AD.

1. Finkelstein JS, Lee M \& Sowers M et al. (2002) JCEM 87(7), 3057-67.

2. Ward KA \& Roy DK et al. (2007) Bone 41(1), 117-21. 